\title{
An Investigation of the Impact An ROV Competition Curriculum has on Stu- dent Interest in STEM, Specifically Technology and Engineering
}

\section{Mr. Daniel Gordon Mendiola Bates, Brigham Young University}

Graduate masters student. Research emphasis in technology and engineering education. For the past 4 years has taught jr. high CTE Technology and Engineering courses. Daniel has recently been accepted to NC State to pursue a doctorate degree in Technology Education.

Dr. Geoff Wright, Brigham Young University

Dr. Geoffrey A. Wright is a professor of Technology and Engineering Education in the Ira A. Fulton College of Engineering and Technology at Brigham Young University.

Dr. Steven L. Shumway, Brigham Young University

Dr. Shumway is an Associate Professor in the Technology and Engineering Education Program at BYU 


\title{
Underwater Robotics Experience Changes Student Interest in sTEm
}

\begin{abstract}
:
This research investigates the impact a Remotely Operated Vehicle (ROV) program has on student interest in, and perception of, technology and engineering (sTEm). ROV programs embed all areas of science, technology, engineering and math (STEM) into their curriculum; however, emphasis for this research is placed on interest and perception of the "T" and "E" of STEM. Although there are many articles detailing the benefits of ROV programs, there is little empirical data documenting the impact on student interest and perception of sTEm. This research paper outlines the background of a couple ROV programs in the U.S.; specifically an ROV statewide program within a landlocked state, the methods for gathering data and findings from a sTEm survey instrument administrated to over 300 junior high aged students who participated in a five-month ROV program and near 50 students who did not. A few of the statistical significant results from the survey show students in the program score higher than those not in the program when asked to rate the following statements on a 5pt Likert agree scale: "I will probably get an engineering job later on" (p value: .019), "If there was a school club about engineering I would certainly join it" ( $p$ value: .021), and "How much do you like science?" ( $p$ value: .014). The entirety of qualitative and quantitative data is not being reported at this time, as it is currently being considered for publication in an engineering journal.
\end{abstract}

\section{Introduction}

There are concerns about the dwindling labor pool of technically trained personnel who have scientific, technical, engineering, and mathematical (STEM) skills and abilities. These areas are vital to American competitiveness in an expanding global economy and technically advancing global market. America's STEM industries need college graduates and others proficient in STEM to meet industrial needs and progressing technological advancements ${ }^{2,4,18}$. Regrettably, according to the National Science Board Science and Engineering Indicators, in the past five years, only 15.6 percent of bachelor's degrees were awarded in STEM fields in America. Among other world competitors the percentage is much higher, for example China and Korea awarded 46.7 and 37.8 bachelor degrees in STEM areas ${ }^{15}$. One of many initiatives attempting to remedy "this" involves the growth and adoption of secondary education STEM project-based learning activities, such as designing, building, and driving remotely operated vehicles (ROVs) ${ }^{7,17,21}$.

ROVs have been used in education as early as 1992 for the purpose of applying science and engineering knowledge, tools and techniques to the understanding and use of the marine environment ${ }^{12}$ and to increase the number of skilled technicians to work in "strategic advancedtechnology fields" "16. Educational programs that have used ROVs suggest ROV-based curriculum and activities can be a tool to enhance interest and improve perception regarding technology and engineering ${ }^{9,14}$. There is, however, limited research on the impact an ROV activity or program makes on increasing student interest and/or perception of technology and engineering. Programs such as SeaPerch ${ }^{1,8}$, Utah Underwater Robotics ${ }^{9,23}$, Summer Bridge Program of $2011^{10}$, Waterbotics ${ }^{7,13}$ and MATE ${ }^{5,24}$ all use underwater robotics as part of STEM 
curriculum. Within each program, online news articles, videos, and various journal and research articles show evidence of increased student engagement and interest in STEM-related areas, in robotics efficacy and STEM learning in general ${ }^{8,13,19}$. Most of the evidence from these ROV programs however, only speaks to the procedures of the activity within STEM, not to valid data from reliable instruments supporting the impact the program is making in student interest and perception of technology and engineering.

\section{Problem Statement}

There is limited research on the impact an ROV activity or program makes regarding student interest and perception of technology and engineering. Furthermore, there is limited research using a reliable survey instrument to investigate attitude/interest and perception of technology, specifically within the constraints of a ROV program. Through this research study, quantitative (survey instruments) and qualitative (focus group and informal interviews) methods were used to investigate the impact of an ROV program in Utah. Survey statements from the PATT-USA, a modified version of the PATT, were added to this year's UUR (Utah Underwater Robotics) ROV survey. The purpose for this was to include questions regarding student interest and perception from a reliable survey instrument. This modified PATT-USA survey was administered to treatment (students who did participate in the 5-month program) and control (students who did not participate) groups.

\section{Research Question}

The research question of this project is: How does participation in a 5-month ROV experience influence 6-8th grade students' interest in, and perception of, technology and engineering?

\section{Background}

There is limited literature that discusses the significance an ROV program has on student interest and perception of technology and engineering in an educational setting. Most of the literature involving the use of ROVs consists of a study or report of the curriculum and experiential design for that particular program. For example, several of the reports include the results of participants' accomplishments, and in some cases participants' perceptions or feelings about the program. Additionally, literature describing the instruments used for analysis of the impact the particular ROV program had on the participants' interest is limited. Because of the limited literature related to this current study, efforts for this study were focused on pertinent literature implementing the use of ROVs as a STEM-related activity in an educational setting and primarily aimed at showing the similarities and differences of programs and practices in comparison to this study's ROV program investigation. The largest ROV program in the U.S. is SeaPerch. It will be discussed below. Additionally, information surrounding the UUR (Utah Underwater Robotics) Competition will also be discussed. Immediately following the definition and descriptions of the two pertinent ROV programs, the topic of interest will be discussed. The purpose of including the topic of interest is to help clarify the primary research question of: How does participation in a 5-month ROV experience influence 6-8th grade students' interest in, and perception of, technology and engineering? 
Underwater ROV programs: What impact do they have on students' interest in, and perception of, sTEm?

Building robots, specifically underwater remotely operated vehicles (ROVs), is one promising and developing approach where the impact indicates an increase in sTEm interest among elementary and secondary students ${ }^{7,10,17,23}$. The building and operating of an underwater ROV is an increasingly popular activity in sTEm education because of its capacity to implement science, technology, engineering, and mathematical principles as part of its function ${ }^{23}$. In the United States there are several ROV programs offering a variety of opportunities to apply engineering-type skills and experiences that may lead to an increase in sTEm interest. The SeaPerch and Utah Underwater Robotics programs are discussed below.

\section{SeaPerch}

For the past 12 years, K-12 students involved in the SeaPerch program have built underwater ROVs and learned about basic engineering and science concepts with a marine engineering theme. The building of an underwater ROV, and applications of ROV-related engineering and science content taught through the program has been designed to meet many learning standards and outcomes according to the curriculum outline on the SeaPerch website. Standards and outcomes include: Ship and submarine design, buoyancy/displacement, propulsion, vectors, electrical waterproofing, soldering, ergonomics, depth measurement, biological sampling, attenuation of light, and moment arm. Basic physics of motion, tool safety and usage, and career possibilities are also included ${ }^{1}$.

Various news articles and media publications involving the SeaPerch program describe the procedures and accomplishments of students participating in the program. One such news article written by Luci Weldon, interviews Marissa Sherrill as she describes her students' actions during a robotics course at Warren New Tech High School in North Carolina, Weldon reports:

Students research the types of robots developed around the world and how they are used in various settings. Students' class work involves cutting PVC pipes, using zip lines to attach the netting to the pipes for buoyancy, drilling holes to allow the vehicle to float, attaching thrusters and propellers, soldering a control panel circuit and stripping wires to connect them with the propellers $^{22}$.

An article on the SeaPerch website provides clear implications of positive impact on student interest in sTEm. Nothing was found that provided research-based data indicating the difference the program made in student interest toward sTEm. As illustrated by one's student's reflection of the SeaPerch program's impact on his thinking, an article in Waves Magazine reported on a regional SeaPerch challenge in Maryland:

STEM influences me by showing me new ways to think and create new engineering ideas. The inventions created through STEM make engineering appealing to me for my future in deciding on college and my career path ${ }^{11}$. 
Additionally, an interview in the Chicago Tribune of Commander Michael Kerley, the Midwest Outreach Officer for SeaPerch, captured the primary learning outcome of the SeaPerch program:

The reason this is so important is that we, as a nation, are losing our current generation of scientists and engineers. So the Navy is trying to build that next generation, using SeaPerch. The Navy is looking, proactively, to engage students in STEM subjects and get them excited ${ }^{3}$.

Another article reports students' imagination being impacted by the SeaPerch program. Devin Heilman quotes one student,

They (ROVs) can probably reach deeper depths in the sea," Ethan said. "I've heard on the news that for some reason our land space is not as much. Maybe someday we can make, like, an underwater robot so that people can live under the water, because there is so much room under the sea. It's just something I've thought about ${ }^{8}$.

Articles such as those presented above suggest SeaPerch is having a positive impact on student interest in sTEm. However, the findings are limited to qualitative self-reporting, and there is limited quantitative reports indicating evidence from data or research on the actual impact the SeaPerch program has on student interest in, and perception of, sTEm.

\section{$\boldsymbol{U U R}$}

The Utah Underwater Robotics (UUR) program recently finished its third consecutive year of operation. UUR was instigated because MIT graduate, Tadd Truscott, then working as a mechanical engineering professor at Brigham Young University (BYU), decided to involve the BYU community in an effort to excite young students about STEM topics ${ }^{9}$. Due to Dr. Truscott's experience with the Office of Naval Research (ONR), the UUR curriculum follows the structure of the SeaPerch program. Initially the program did not have a research agenda, however, as planning stages progressed it was decided to include a survey instrument.

For the first year of UUR, a survey instrument was developed which assessed each student's interest and self-efficacy in STEM ${ }^{23}$. The assessment was influenced by related STEM assessments, such as the STEM semantics survey and the STEM Career interest Questionnaire ${ }^{20}$. The assessment asked questions regarding students understanding of STEM principles, interest in STEM topics, careers, and fields of study. According to Wright, in that first year of study, quantitative data received from the surveys did not reveal that the ROV activity had made any statistically significant impact on student interest in STEM areas. Researchers still believed, however, based on observations, and on teacher, student, and administrative feedback, that the ROV program had potential to impact student interest in STEM. Researchers acknowledged the need to further develop and improve research methods, curriculum, and associated theories. Wright reported that:

Additionally, we intrinsically believe (based on personal beliefs and observations) that contemporary and blended STEM curriculum such as ROV (underwater technology) can effectively promote STEM interest and ability. Therefore, there is a need to develop and evaluate the curriculum and associated theories. This research effort is a start in this direction ${ }^{23}$. 
The purpose of this current research is to expand, develop, and evaluate the theories identified by Wright. For example, the UUR program lacks a qualitative component investigating the impact an ROV program has on student interest in, and perception of, technology and engineering (sTEm). It is the belief of the researcher that by adding a qualitative component to the current study, it may be possible to determine statistical significance of the impact UUR has on student interest in sTEm, by triangulating data from both an improved sTEm survey and interviews and field notes. If accomplished, data and methods from this study may assist other ROV programs determine significance and improve implementation of similar STEM activities specifically those focused on technology and engineering.

\section{Interest}

The purpose of this study is to investigate the question, "How does a five-month ROV curriculum and competition impact student interest in, and perception of, sTEm?" In light of the focus on interest we believed there is a need to clarify what "interest" means.

In the study titled, Igniting and Sustaining Interest Among Students Who Have Grown Cold Toward Science, Jack et al. (2014) present three characteristics of the nature of interest, which helps define interest.

- Interest is biased in disposing a person toward certain behaviors only if an object or activity of interest is present.

- Interest is dynamic in disposing the person toward seeking out additional experiences that provide continued or repeated interaction with the interest object or activity.

- The third characteristic of interest is its mediated changeableness, which is affected by the process of internalization and refers literally to the taking in of something from the outside.

Dewey (1913) Presents more detail about how such mediated changeableness of interest is indirect or transferred interest,

We have cases of indirect, transferred, or technically speaking, mediated interest. Things indifferent or even repulsive in themselves often become of interest because of assuming relationships and connections of which we were previously unaware. Many a student, of so-called practical make-up, has found mathematical theory, once repellent, lit up by great attractiveness after studying some form of engineering in which this theory was a necessary tool ${ }^{6}$. (p. 22)

An example of biased interest relating to underwater ROVs would be students learning science, engineering, and technology content embedded in the ROV curriculum without understanding how such learning is meaningfully relevant to their lives. It is only when students are able to see and understand how the learning of science, engineering and technology content embedded in the UUR curriculum is meaningfully relevant to them, that interest moves from biased to mediated interest internalized.

These literature points from Dewey and Jack et al. help clarify what is meant by interest by identifying key characteristics of interest and defining what an outcome of interest should be. 
This is important to this study because in trying to measure change in student interest, without having a clear understanding of what we are looking for it, it would be difficult to make claims about change in interest.

\section{Research Methods}

The data was collected in three formats. The first one was through observations made at the Utah Underwater Robotics 3rd annual ROV competition held March 18, 2015. The second was based on students' control and treatment group responses from a technology and engineering interest survey. The third came from focus group interviews with 54 elementary students who participated in the UUR ROV competition. Both data collection methods are briefly discussed below.

\section{Observations}

Notes and observations of over 400 students preparing and competing using their personally built ROV, were collected during the 3rd annual Utah Underwater Robotics competition, held on March, 18th 2014, in Lehi Utah. The local recreation center included a 25yard, 8-lane pool where students conducted their ROV team challenges.

A few teachers, principles, and students were semi-randomly selected (meaning, as participants arrived or seemed to have time, the researcher would engage them in a conversation. The researcher made an effort to talk with an equal number of male and female students, administrators, teachers, and parents. He did this by keeping track in his field notes). Teachers and principals were asked questions such as: What impact do you think this ROV program has on the students? Did you see a difference in student behavior or engagement in STEM related activities and or curriculum before or after engaging in the ROV related activities and curriculum? What do you think the program teaches students? What would you say is the best thing about the program?

Students were asked questions such as: What was one thing you learned from this experience? How did you build your ROV? What was the best part of your experience? Would you do this again if you had the chance? Teams were also asked questions about how prepared they felt for the competition. Questions were influenced by the overall purpose of the research: investigating how an ROV program impacts student interest in, and perception of technology and engineering.

Observations also included the reactions and comments students were having with each other during their assigned competing time-slot. Students were observed as they came into the building and swimming pool arena. Teams were observed as they waited their turn to compete. Students', parents' and teachers' behavior and conversations after the competition, and their reactions during the awards ceremony were all observed and noted.

The focus group interview findings will not be reported in this paper. However, some quantitative data collected from the surveys will be reported and discussed. 


\section{Survey}

A survey was administered to students in a treatment group (students who participated in the UUR--Utah Underwater Robotics - competition), and a control group (those who did not participate). Students who participated in the program were a result of their particular teacher volunteering to participate. Thus, students with and without interest in the program are included in the study's sample. The treatment group consisted of 280 survey responses, $62 \%$ male, grade levels $3^{\text {rd }}(10 \%), 6^{\text {th }}(5 \%) 7^{\text {th }}(30 \%) 8^{\text {th }}(45 \%)$ and $9^{\text {th }}(10 \%)$, and $80 \%$ Caucasian students. As administrators of the UUR we did not have control over how often the students met to work on their ROVs, nor were we able to determine how well, or what the teachers taught.

Notwithstanding, participating teachers were asked to ensure their students (said treatment group) completed the modified PATT survey instrument after the associated ROV competition. Likewise, non-participating teachers were expected to ensure their students completed the survey. The control group consisted of 47 survey responses, $48 \%$ male, $6^{\text {th }}$ graders from the same school as one of the treatment group's $6^{\text {th }}$ grade classes and $80 \%$ Caucasian students.

The survey was sent out to 19 participating teachers, potentially reaching 458 treatment group students. Of the potential 458 students, we received 302 student responses and after data cleaning, 280 responses were determined useable. After determining the useable data our effective response rate was 61 percent.

\section{Findings}

The analysis of the data consisted of aggregating data in JMP and performing various descriptive statistics, namely the Wilcoxon Signed-Rank Test and Dunn's Method for Joint Ranking. This is a nonparametric test equivalent to the dependent t-test. It is used to compare two sets of scores that come from the same participants in a non-normal data set. Because our data resulted from a treatment and control survey, and because our data does not fit within a normal distribution, it was believed a Wilcoxon rank sums test would be the most appropriate data analysis test. To clarify, results from the modified PATT survey instrument were compared from treatment to control.

The findings reveal that student interest in engineering careers $(\mathrm{p}=0.01)$ and the desire to join a school club about engineering $(\mathrm{p}=0.01)$ were significantly different. Additionally, student self-efficacy in science was also significant $(\mathrm{p}=0.0076)$. Table 1.1 outlines the survey question and associated data results. Note that when the p-value is less than 0.05 , then the $95 \%$ confidence interval will not contain zero, suggesting that the difference between the treatment and control test results would rarely occur due to random sampling. Thus we can conclude the results of these questions are significant results and should be further investigated.

One of the qualitative pieces lending some insight into this quantitative reporting is that many teachers implementing the ROV activity within the scope of the UUR competition were science teachers (45\%). There were also $30 \%$ technology teachers, and $20 \%$ elementary teachers (the $6^{\text {th }}$ grade students are considered elementary students), and 5\% of the teachers were part of homeschool programs. In light of the finding that student interest in science increased after 
participating in this ROV activity, hands-on application type activities may be an important factor when teachers are designing science and engineering related curriculum.

\begin{tabular}{|l|l|l|}
\hline Question & $\begin{array}{l}\text { Treatment - Control } \\
\text { Comparison }\end{array}$ & $\begin{array}{l}\text { Sum Score } \\
\text { Difference }\end{array}$ \\
\hline $\begin{array}{l}\text { I will probably get a job in Engineering later } \\
\text { on }\end{array}$ & p-value $=.0105$ & 37.46 \\
\hline $\begin{array}{l}\text { If there was as school club about } \\
\text { engineering, I would certainly join it }\end{array}$ & p-value $=.0114$ & 37.44 \\
\hline Engineering makes everything work better & p-value $=.0025$ & 44.59 \\
\hline Engineering is important in life & $p$-value $=.0006$ & 49.88 \\
\hline $\begin{array}{l}\text { An engineer is someone who uses science to } \\
\text { build new and useful things }\end{array}$ & p-value $=.0407$ & 28.54 \\
\hline How good are you at science & p-value $=.0076$ & 38.61 \\
\hline
\end{tabular}

Table 1.1: Survey Questions

\section{Conclusions}

Nationally there is a movement to promote more STEM education in K-12 and upper education. Various programs, curriculum, and activities are being implemented. Robotics has been a popular potential solution cadre, where VEX, Mindstorms, ROVs are being regularly implemented. Within the ROV literature there is a limited amount of research detailing the impact ROV related curriculum or activities are having on student interest in STEM.

The findings of this research project suggest that a competition-based curriculum involving ROV technology can make a difference increasing student interest in engineering and science. Although this project only investigated the holistic effect on the general student competitor population at the UUR event, the researchers believe that if a limited curriculum such as that connected to the UUR competition made a significant impact on student interest, that a more robust curriculum implementation with more precise curriculum learning objectives would have a larger impact on student interest and ability in STEM related subject matter. The researchers of this project suggest that educational stakeholders evaluate their current STEM curriculum and activities, investigate the impact they are having, and at a minimum incorporate more hands-on engineering activities that highlight scientific principles. The researchers of this project believe that the ROV activity described above is what contributed to the increase in student interest in engineering and science - however, they are keenly aware that perhaps the results are equally representative of simply having an engaging hands-on engineering activity that highlighted immediately applicable scientific principles. Further research should consider investigating this phenomenon. 


\section{References}

$1 \quad$ AUVSI Foundation, 'What Is Seaperch?', AUVSI Foundation, (2013)

$<$ http://www.seaperch.org/what is $\% 3 \mathrm{E}$.

2 BHEF, 'Increasing the Number of Stem Graduates: Insights from the U.S. Stem Education and Modeling Project', (2010).

3 Denys Bucksten, 'Students' Robots Test the Waters at Naval Station Great Lakes', Chicago Tribune 2015.

4 Roger W.; Fuchs Bybee, Bruce 'Preparing the 21st Century Workforce: A New Reform in Science and Technology Education', Journal of Research in Science Teaching, 43 (2006), 349-56.

5 L. Clough, and T. Lundsford, 'The Mate Technical Internship Program: Providing Students with Hands-on, Real World Workplace Experiences and Employers with Future Employees', in OCEANS 2006 (Boston, MA: IEEE, 2006), pp. 1-3.

6 John Dewey, Interest and Effort in Education (Boston, NY: Houghton Mifflin Company, 1913).

7 Amy Eguchi, 'Robotics as a Tool for Educational Transformation', in International Conference Robotics in Education (Padova, Italy: 2014), pp. 27-34.

8 Devin Heilman, 'Seaperch Program Creates Waves of Imagination', CDAPress.com 2015.

9 Randy C.; Hacking Hurd, Kip S.; Damarjian, Jennifer L.; Wright, Geoffrey A.; Truscott, Tadd 'Underwater Robots Surface in Utah', Technology and Engineering Teacher, 74 (2013).

10 Baha; Pee Jassesmnejad, Wei Siang; Rada, Kevin; Keith, Devin Kelly; Miller, Dylan Bradley; Lemley, Evan C.; Dorety, Adam 'Transformative Learning Experience: Underwater Robotics Research', American Society for Engineering Education (2012).

11 Nicholas Malay, 'Students Hone Stem Skills at Maryland Regional Seaperch Challenge', Waves Magazine 2014.

12 MATE, 'About the Mate Center'2015) < http://www.marinetech.org/about/\%3E.

13 Beth; Sayres McGrath, Jason; Lowes, Susan; Lin, Peiyi, 'Underwater Lego Robotics as the Vehicle to Engage Students in Stem: The Build It Project's First Year of Classroom Implementation', American Society for Engineering Education Mid-Atlantic, Hoboken, NJ (2008). Alan; Cohen Melchior, Faye; Cutter, Tracy; Leavitt, Thomas; Manchester, NH; 'More Than Robots: An Evaluation of the First Robotics Competition Participant and Institutional Impacts', Heller School for Social Policy and Management, Brandeis University (2005).

15 National Science Board, 'Earned Bachelor's Degrees, by Citizenship, Field, and Race/Ethnicity: ' in National Science Board Science and Engineering Indicators (Arlington, VA: NSB, 2010).

16 C. Reid Nichols, and Robert G. Williams, 'Marine Advanced Technology Education (Mate) Center', in Encyclopedia of Marine Science (New York, NY: Facts On FIle, Inc., 2009). Gwen; Barker Nugent, Bradley; Grandgenett, Neal; Adamchuk, Viachaslav I., 'Impact of Robotics and Geospatial Technology Interventions on Youth Stem Learning and Attitudes', Journal of Research on Technology in Education, 42 (2010), 391-408.

18 Jonathan Rothwell, 'The Hidden Stem Economy', (Brookings, 2013).

19 Rustam; Hotaling Stolkin, Liesl; Sheryll, Richard; Sheppard, Keith; Chassapis, Constantin; McGrath, Elisabeth 'A Paradigm for Vertically Integrated Curriculum Innovation-How Curricula Were Developed for Undergraduate, Middle and High School Students Using Underwater Robotics', in International Conference of Engineering Education (2007). Tandra Tyler-Wood, Gerald Knezek, and Rhonda Christensen, 'Instruments for Assessing Interest in Stem Content and Careers', Journal of Technology Teacher Education, 18 (2010), 341-63.

21 Anita; Huffman Welch, Douglas, 'The Effect of Robotics Competitions on High School Students' Attitudes toward Science', School Science and Mathematics, 111 (2011), 416-24. Luci Weldon, 'Students Test Underwater Vehicles at Robotics Expo', The Warren Record 2015.

Geoff A.; Hurd Wright, Randy; Hacking, Kip S.; Truscott, Tadd, 'Using Rovs to Teach a Blended Stem Curriculum', American Society for Engineering Education (2014).

J. Zande, and D. Sullivan, 'Rov Competitions for Students: Developing the Next Generation of Ocean Explorers, Scientists, Technologists, and Engineers.', in OCEANS 2003 (San Diego, CA.: IEEE, 2003), pp. 1563-64. 
